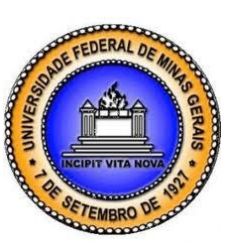

\title{
AVALIAÇÃO DA GESTÃO DE CUSTOS NAS ENTIDADES HOSPITALARES: UM ESTUDO NA CIDADE DE UBERLÂNDIA MG ${ }^{1}$
}

\author{
EVALUATION OF COST MANAGEMENT IN HOSPITALS: A STUDY IN THE \\ CITY OF UBERLÂNDIA, BRAZIL
}

\section{EVALUACIÓN DE LOS COSTES DE GESTIÓN DE ENTIDADES EN HOSPITAL: UN ESTUDIO EN LA CIUDAD DE UBERLÂNDIA MG}

\author{
Maria Eliana dos Santos \\ Universidade Federal de Uberlândia. \\ m.elianasantos@yahoo.com.br
}

\author{
Vidigal Fernandes Martins \\ Universidade Federal de Uberlândia. \\ vidigal@ufu.br
}

\author{
Edvalda Araújo Leal \\ Universidade Federal de Uberlândia. \\ edvalda@facic.ufu.br
}

\begin{abstract}
Resumo
Este artigo apresenta os resultados de uma pesquisa de campo realizada nos hospitais localizados na cidade de Uberlândia-MG, com objetivo de avaliar a utilização das informações de custos nas entidades hospitalares. Os hospitais possuem alta complexidade na operacionalização de suas atividades, exigindo dos gestores deste setor um maior empenho em obter um tratamento empresarial que proporcione eficiência suficiente para realizar seu negócio com credibilidade junto a seus clientes e mantendo uma condição econômico financeira que viabilize a competitividade da empresa. A metodologia utilizada caracteriza-se por um estudo exploratório. Para a coleta de dados, utilizou-se da pesquisa bibliografia, entrevista não-estruturada e questionário. Os resultados apontam que no grupo dos hospitais investigados, foi observada uma aplicação parcial da gestão de custos no processo decisório. Verificou-se que os gestores percebem a necessidade e a importância da informação de um sistema de custos para que se possa subsidiar de forma eficiente e eficaz o processo decisório e buscar a sustentabilidade econômico-financeira da organização.
\end{abstract}

Palavras-chave: Hospital. Custos. Gestão.

\begin{abstract}
This article presents the results of a field study carried out in hospitals in the city of Uberlândia, Brazil, aiming to evaluate the use of cost information in hospitals. Hospitals are highly complex in the operationalization of their activities, demanding managers in this sector to make higher efforts to attain an efficient enough business treatment to credibly do business with clients, maintaining economic and financial conditions that facilitate the competitiveness of the company. Methodologically, an exploratory study was done. Data collection was done through bibliographical research, unstructured interviews, and a questionnaire. Results have shown that among the hospitals investigated, cost managed was applied to only part of the decision-making process. It was clear that managers do realize the importance and need of information from a cost system to efficiently and effectively subsidize the decision-making process and to aim for the economic and financial sustainability of the organization.
\end{abstract}

Keywords: Hospital. Costs. Management.

\section{Resumen}

En este artículo se presentan los resultados de un estudio de campo realizado en los hospitales ubicados en la ciudad de Uberlândia-MG, para evaluar el uso de la información de costos en las entidades hospitalarias. Los

\footnotetext{
${ }^{1}$ Submetido em 16 de Outubro de 2012. Aceito em 30 de Novembro de 2012. O artigo foi avaliado segundo o processo de duplo anonimato além de ser avaliado pelo editor. Editores responsáveis: Márcio Augusto Gonçalves e Lucas Maia dos Santos. Reprodução parcial ou total e trabalhos derivativos permitidos com a citação apropriada da fonte.
} 
hospitales tienen una alta complejidad en el funcionamiento de sus actividades, que requieren los administradores de este sector un mayor compromiso de obtener negocio de tratamiento que proporciona lo suficientemente eficaz para hacer su negocio con la credibilidad con los clientes y el mantenimiento de una situación económica financiera que facilita la competitividad de la empresa . La metodología se caracteriza por un estudio exploratorio. Para la recolección de los datos, se utilizó la literatura de investigación, la entrevista no estructurada y un cuestionario. Los resultados muestran que el grupo de los hospitales encuestados, hubo una aplicación parcial de la gestión de costos en la toma de decisiones. Se encontró que los gerentes se dan cuenta de la necesidad y la importancia de los costos de un sistema de información para que podamos apoyar una toma de decisiones eficiente y eficaz y buscar la sostenibilidad económica y financiera de la organización.

Palabras clave: Hospital. Costos. Administración.

\section{Introdução}

$\mathrm{Na}$ sociedade contemporânea, ocorrem significativas transformações que levam as organizações a buscarem novos modelos de negócios e, ainda, a reorganização de seus processos produtivos a partir do investimento em novas tecnologias e da introdução de novas práticas de gestão, visando à melhoria da competitividade.

As organizações hospitalares que possuem um grau de complexidade e altos níveis de gastos incorridos na produção de serviços têm buscado prestar um serviço diferenciado, ou seja, o bem-estar do paciente, investindo em tecnologias avançadas e capacitação técnica de mão-de-obra, com vistas a manter a qualidade de serviços.

Atualmente, os países desenvolvidos mergulharam na pior crise financeira das últimas décadas, e a extensão dos problemas causa uma incerteza e afeta o mercado mundial. A redução drástica de crédito, reflexo desta crise, já começa a ser sentida no Brasil. Nesse contexto, as entidades hospitalares deparam-se com a instabilidade da economia. Estas entidades submetem-se frequentemente a investimentos e renovação do nível de tecnologia médica, e a maioria de seus equipamentos são adquiridos no mercado externo, além de possuírem dependência das indústrias farmacêuticas, aumentando assim seus custos.

Nesse cenário, percebe-se o aumento dos gastos, o crescimento da competitividade global, a concorrência e a pressão com a crise econômica, fazendo com que as empresas busquem desenvolver ferramentas de gestão mais eficazes.

Atualmente, a gestão hospitalar brasileira é considerada um dos setores mais defasados quanto à utilização das ferramentas de gestão econômico-financeira, ocasionando, por exemplo, baixa produtividade, elevados desperdícios de recursos e desconhecimento do custo real dos procedimentos (CADERNOS DO TERCEIRO MUNDO, 1999; CARPINTÉRO, 1999 e CECÍLIO, 1997).

A Associação Americana de Hospitais (AHA), já em 1980, considerou os hospitais como organizações complexas para a prestação de atividades altamente relevantes à sociedade. Segundo Médici (1996), “O Brasil não está assim muito distante do que vêm acontecendo nos Estados Unidos com respeito a elevação dos custos na área da saúde”. Nesse ambiente competitivo, torna-se desafiador e estratégico o conhecimento dos custos dos serviços prestados para qualquer organização. Dessa forma, as organizações vêm buscando melhorar seus processos de gestão.

As mudanças no Brasil começaram no final dos anos 90, com o aumento da competitividade num mercado desacostumado a operar tendo como norte o lucro. A pressão por eficiência e custo baixo passou a serem metas cada vez mais buscadas pelos administradores dentro dos hospitais. Cherubin e Santos (2002, p. 109). 
As organizações hospitalares apresentam em sua operacionalização procedimentos significativos na prestação de serviços de saúde à comunidade, e se empenham em obter desempenho empresarial que proporcione credibilidade e sustentabilidade econômicofinanceira. Assim, a questão problema deste estudo é: Como as Entidades hospitalares utilizam a gestão de custos em suas atividades operacionais, bem como para a tomada de decisão?

Para responder a questão, o estudo tem como objetivo principal avaliar a utilização das informações de custos nas entidades hospitalares. A pesquisa de campo foi realizada nos hospitais localizados na cidade de Uberlândia-MG.

Este artigo está estruturado da seguinte forma: inicialmente, é apresentada uma breve contextualização da Contabilidade de Custos e os Métodos de Custeio; na sequência, a gestão de custos nas organizações hospitalares. Posteriormente, são descritos os procedimentos metodológicos realizados e os resultados obtidos, e por fim as conclusões do estudo.

\section{Referencial Teórico}

\subsection{A Contabilidade de Custos e os Métodos de Custeio}

A contabilidade de Custos consolidou-se com o objetivo de definir o valor dos custos de fabricação dos produtos estocados, todo um sistema de registro, acompanhamento, apropriação e rateio de gastos, bem como todos os lançamentos contábeis e controles paralelos (MARTINS, 2003).

Para Leone (2000, p.19), Contabilidade de custos é o ramo da contabilidade que se destina a produzir informações para os diversos níveis gerenciais de uma entidade, como auxílio às funções de determinação de desempenho, de planejamento e controle das operações e de tomada de decisões.

Os sistemas de custos se desenvolveram a partir de uma crescente necessidade de aprimorar os métodos de avaliação dos estoques nas empresas industriais, principalmente, quando um significativo volume de produtos em elaboração exigia uma acurada medição e consequente valorização dos inventários. Com a Revolução Industrial, as empresas apresentavam processos de produção muito semelhantes aos processos artesanais e compunham as suas matrizes de custos, basicamente, com matérias-primas e mão-de-obra que eram, sem dúvida, os mais relevantes (MATTOS, 2003).

Com o crescimento das empresas e o consequente aumento na complexidade do sistema produtivo, constatou-se que as informações fornecidas pela Contabilidade de Custos eram potencialmente úteis ao auxílio gerencial, função esta tão importante na maioria das empresas quanto à determinação do resultado do período. Os sistemas de custos podem ajudar a gerência da empresa basicamente de duas maneiras: auxílio ao controle e às tomadas de decisões (HORNGREN et al., 2004).

O controle de custos deve ser estruturado de maneira a fornecer resposta aos questionamentos dos gestores quanto à origem e destino de cada gasto. Segundo Martins (2003, p.37), custeio significa apropriação de custos, destacando entre eles, o custeio por absorção, o custeio direto ou variável, o custeio integral ou RKW, custeio padrão e o custeio baseado em atividade - ABC, que serão apresentados a seguir.

Martins (2003, p.37) considera que o custeio por absorção consiste na apropriação de todos os custos de produção aos bens elaborados e só os de produção, todos os gastos relativos ao esforço de produção são distribuídos para todos os produtos ou serviços feitos. Apropriam todos os custos de produção, tanto os fixos como os variáveis.

No custeio variável, segundo Martins (2003, p.198), "só são alocados aos produtos os custos variáveis, ficando os fixos separados e considerados como despesas do período, indo 
diretamente para o Resultado, para os estoques só vão os custos variáveis”. Esse sistema, mesmo sendo difundido, não é muito utilizado, visto que não é aceito pelo físco, pois contraria os Princípios Fundamentais de Contabilidade - competência e confrontação, uma vez que antecipa a ocorrência do custo indireto de produção. Além disso, o sistema subestima a avaliação dos estoques, o que resulta em valores de custo e estoques mais baixos do que aqueles detidos pelo critério do custeio por absorção.

De acordo com Santos (1999, p. 66), o sistema de custeio integral "caracteriza-se pela apropriação de todos os custos e despesas aos produtos fabricados", ou seja, são alocados todos os custos e despesas fixas e variáveis e custos diretos e indiretos aos produtos fabricados. Para Martins (2003, p.220), consiste no rateio dos custos de produção e todas as despesas da empresa a todos os produtos. Com esse rateio chega-se ao custo de produzir e vender, dando o gasto completo de todo o processo empresarial de obtenção de receita, bastando adicionar o lucro desejado para se ter o preço de venda final.

Conforme Vatanian e Nascimento (1999), o custeio integral é basicamente utilizado para fins de controle dos custos e análise gerencial, pois a sua importância está em auxiliar o gestor no controle e planejamento do total dos custos e despesas, bem como facilitar a minimização dos gastos totais de uma empresa num determinado período.

Mats, Curry e Frank (1987, p. 532) definem custo padrão como o custo planejado de um produto, segundo condições de operação correntes e/ou previstas. Martins (2008, p.316) considera que a finalidade do custeio padrão é o planejamento e controle de custos, com objetivo de fixar uma base de comparação entre o que ocorreu de custo e o que deveria ter ocorrido.

Leone (2000, p. 286) ressalta que "o sistema de custo-padrão não tem utilidade se for implantado solitariamente", pois precisa ser implantado juntamente com outro sistema de custeio que forneça os custos reais. Por suas características, esse método é utilizado apenas para fins gerenciais, com finalidade de apontar deficiências na linha de produção.

Referente ao custeio baseado em atividades - ABC, Bornia (2002, p. 121) considera que "a idéia básica do $\mathrm{ABC}$ é tomar os custos das várias atividades da empresa e entender seu comportamento, encontrando bases que representam as relações entre os produtos e essas atividades". Na visão de Martins (2003, p.87), o ABC é um método de custeio que procura reduzir sensivelmente as distorções provocadas pelos rateios arbitrários dos custos indiretos.

Esse sistema visa demonstrar claramente todos os custos absorvidos durante o processo, dividindo-os por atividades, utilizando um direcionador para a alocação dos custos indiretos.

Perez (1999, p. 227) considera o ABC uma técnica de controle e alocação dos custos envolvidos nos processos e atividade, que permite identificar os processos e as atividades existentes nos setores produtivos, auxiliares ou administrativos de uma organização e atribuir os custos aos produtos, tendo como parâmetro a utilização dos gestores de custos. Além disso, o método rateia todos os custos e despesas aos produtos, bastando adicionar o lucro que deseja obter. Evidenciando-se a alocação mais racional de custos e despesas.

Apresentamos a seguir uma síntese (Quadro 1) que resume os sistemas de custos descritos anteriormente, ressaltando algumas características, como: o conceitos, forma de cálculo, utilidade e finalidades de apuração de custos.

\begin{tabular}{|c|c|c|c|c|c|}
\hline Custeio & RKW & $\begin{array}{c}\text { Por Absorção ou } \\
\text { Tradicional }\end{array}$ & $\begin{array}{c}\text { Direto ou } \\
\text { Variável }\end{array}$ & $\begin{array}{c}\text { Custeio } \\
\text { Padrão }\end{array}$ & Custeio ABC \\
\hline \multirow{3}{*}{ Conceito } & $\begin{array}{c}\text { Método pelo } \\
\text { qual todos os } \\
\text { gastos de }\end{array}$ & $\begin{array}{c}\text { Método de } \\
\text { custeio que } \\
\text { período } \\
\text { incorpora aos } \\
\text { produtos e }\end{array}$ & $\begin{array}{c}\text { Método de } \\
\text { custeio que } \\
\text { incorpora aos } \\
\text { produtos e } \\
\text { serviços }\end{array}$ & $\begin{array}{c}\text { É método } \\
\text { de fixar uma } \\
\text { base de } \\
\text { comparação } \\
\text { entre o que }\end{array}$ & $\begin{array}{c}\text { É uma } \\
\text { metodologia que } \\
\text { surgiu como } \\
\text { instrumento da } \\
\text { análise }\end{array}$ \\
\hline
\end{tabular}




\begin{tabular}{|c|c|c|c|c|c|}
\hline & $\begin{array}{l}\text { despesas) } \\
\text { eram } \\
\text { apropriados à } \\
\text { produção por } \\
\text { meio de } \\
\text { técnicas de } \\
\text { rateio. }\end{array}$ & $\begin{array}{l}\text { custos de } \\
\text { produção. }\end{array}$ & $\begin{array}{l}\text { somente os } \\
\text { custos } \\
\text { variáveis. }\end{array}$ & $\begin{array}{l}\text { ocorreu e o } \\
\text { que deveria } \\
\text { ter ocorrido. }\end{array}$ & $\begin{array}{c}\text { estratégica de } \\
\text { custos } \\
\text { relacionados com } \\
\text { as atividades que } \\
\text { mais impactam o } \\
\text { consumo de } \\
\text { recursos de uma } \\
\text { empresa. }\end{array}$ \\
\hline $\begin{array}{l}\text { Utilizado pela } \\
\text { Contabilidade }\end{array}$ & $\begin{array}{c}\text { Não } \\
\text { encontrado. }\end{array}$ & Oficial. & Gerencial. & Gerencial. & Gerencial. \\
\hline Finalidade & Precificação. & $\begin{array}{c}\text { Atender a } \\
\text { legislação } \\
\text { tributária e } \\
\text { societária, apurar } \\
\text { os custos dos } \\
\text { produtos e dos } \\
\text { departamentos. }\end{array}$ & $\begin{array}{c}\text { Serve como } \\
\text { ferramenta } \\
\text { para tomada de } \\
\text { decisões } \\
\text { gerenciais. }\end{array}$ & $\begin{array}{c}\text { Apontar } \\
\text { deficiências } \\
\text { na linha de } \\
\text { produção. }\end{array}$ & $\begin{array}{c}\text { Melhoria dos } \\
\text { processos e das } \\
\text { atividades. Apura } \\
\text { o custo dos } \\
\text { produtos e dos } \\
\text { departamentos. }\end{array}$ \\
\hline $\begin{array}{l}\text { Atende aos } \\
\text { princípios }\end{array}$ & $\begin{array}{c}\text { Não } \\
\text { encontrado. }\end{array}$ & Sim. & Não. & $\begin{array}{l}\text { Sim, com } \\
\text { ajustes }\end{array}$ & Não encontrado. \\
\hline Cálculo & $\begin{array}{c}\text { Despesas e } \\
\text { custos eram } \\
\text { apropriados } \\
\text { na produção. }\end{array}$ & $\begin{array}{c}\text { Despesas } \\
\text { separadas dos } \\
\text { custos e } \\
\text { apropriadas } \\
\text { diretamente ao } \\
\text { Resultado do } \\
\text { Exercício. }\end{array}$ & $\begin{array}{c}\text { Despesas e } \\
\text { custos } \\
\text { variáveis são } \\
\text { alocados aos } \\
\text { produtos e os } \\
\text { fixos são } \\
\text { considerados } \\
\text { despesas do } \\
\text { período. } \\
\end{array}$ & $\begin{array}{l}\text { Precisa ser } \\
\text { implantado } \\
\text { juntamente } \\
\text { com outro } \\
\text { sistema de } \\
\text { custeio que } \\
\text { forneça os } \\
\text { custos reais. }\end{array}$ & $\begin{array}{c}\text { Os custos } \\
\text { ocorrem a partir } \\
\text { da execução de } \\
\text { atividades ( todo } \\
\text { e qualquer evento } \\
\text { que consome } \\
\text { recursos da } \\
\text { empresa. }\end{array}$ \\
\hline Custos & $\begin{array}{l}\text { Não havia } \\
\text { separação. }\end{array}$ & $\begin{array}{c}\text { No início não } \\
\text { havia separação. }\end{array}$ & $\begin{array}{l}\text { Divisão dos } \\
\text { custos em } \\
\text { variáveis e } \\
\text { fixos. }\end{array}$ & $\begin{array}{l}\text { Divisão dos } \\
\text { custos em } \\
\text { variáveis e } \\
\text { fixos para } \\
\text { acompanham } \\
\text { ento das } \\
\text { variações. }\end{array}$ & $\begin{array}{l}\text { A execução da } \\
\text { atividade } \\
\text { determina o } \\
\text { consumo dos } \\
\text { recursos da } \\
\text { empresa, e, } \\
\text { portanto, dos } \\
\text { custos de } \\
\text { produção. }\end{array}$ \\
\hline Despesas & $\begin{array}{c}\text { Eram } \\
\text { irrelevantes. }\end{array}$ & $\begin{array}{l}\text { Relevantes e } \\
\text { separada dos } \\
\text { custos. }\end{array}$ & $\begin{array}{l}\text { Divisão das } \\
\text { despesa em } \\
\text { variáveis e } \\
\text { fixas. }\end{array}$ & $\begin{array}{l}\text { Relevantes e } \\
\text { separadas dos } \\
\text { custos. }\end{array}$ & $\begin{array}{c}\text { Não encontrado, } \\
\text { pois baseia-se nos } \\
\text { gastos indiretos. }\end{array}$ \\
\hline
\end{tabular}

Quadro 1: Principais Sistemas de Custeio

Fonte: adaptado de OLIVEIRA; PEREZ JR (2000); COGAN (2002)

Verifica-se que são vários os métodos de custeio, e cada um deles possui finalidades diferenciadas, as informações fornecidas pela contabilidade de custos são potencialmente úteis ao processo decisório das organizações.

\subsection{Gestão de Custos nas Entidades Hospitalares}

Com a evolução da contabilidade de custos e a competitividade pressionando todas as organizações, as empresas da área de prestação de serviços, principalmente as hospitalares, por se tratarem de organizações complexas, sentem a necessidade de conhecer seus custos, mas encontram grandes dificuldades para implantação de um sistema de custos por desconhecimento, insegurança, falta de estratégia e até mesmo por não disporem de um 
profissional altamente qualificado na gestão de custos, subsidiado por um sistema de informação adequado para a gestão de custos.

De acordo com a Organização Mundial da Saúde (OMS), os objetivos básicos de um hospital são os de prevenir, diagnosticar, curar as doenças; desenvolver pesquisas; e treinar e educar pessoas para geração de saúde. Os administradores das organizações hospitalares buscam a excelência em oferecer esses serviços.

Segundo Almeida (1983, p. 205),

[...] hospital é uma instituição destinada ao diagnóstico e tratamento de doentes internos e externos; planejada e construída ou modernizada com orientação técnica; bem organizada e convenientemente administrada consoante padrões e normas estabelecidas, oficial ou particular, com finalidades diversas; grande ou pequena; custosa ou modesta para atender os riscos, os menos afortunados, os indigentes e necessitados, recebendo doentes ou contribuintes; servindo ao mesmo tempo para prevenir contra a doença e promover a saúde, a prática a pesquisa e o ensino da medicina e da cirurgia, da enfermagem e da dietética, e das demais especialidades a fins.

Atualmente, a organização hospitalar é uma das mais complexas, não apenas pela nobreza e amplitude da sua missão, mas, sobretudo, por apresentar uma equipe multidisciplinar com elevado grau de autonomia, para dar assistência à saúde em caráter preventivo, curativo e reabilitador aos pacientes em regime de internação, em que se utiliza tecnologia de ponta e de rotina e crescentemente (AZEVEDO, 1993).

As organizações hospitalares diferem de outros tipos de organizações, pois suas atividades possuem características próprias. Para Bittencourt (1999. p.48):

[...] as instituições de saúde são tidas como organizações complexas, visto a sua capacidade única de atuar na prestação de serviços de saúde à sociedade. $\mathrm{O}$ autor destaca os recursos humanos e o alto nível de atividades desenvolvidas por um hospital, como: profissionais com alto nível de especialização (como médicos e enfermeiros), atividades com elevada escala de produção (como lavanderia, nutrição e higienização), atividades de uso intensivo de equipamento (como radiologia, laboratório e centro de tratamento intensivo), além das atividades administrativas e de engenharia de apoio.

Nesse contexto, a gestão de custos para as organizações hospitalares tornou-se relevante. Assim, vale destacar alguns aspectos reunidos no trabalho de Abbas (2001, p.12) sobre a situação atual dos hospitais no Brasil e que justificam a importância da discussão do tema 'custos' em organizações de serviços hospitalares: os preços cobrados pelos hospitais brasileiros são altos; as novas tecnologias implementadas nos hospitais deram uma nova cara ao modo de operar dos mesmos, o que, certamente, alterou sua estrutura de custos; má administração; custos mal elaborados ou desconhecidos; os hospitais reclamam que são mal remunerados, dentre outros.

Outro aspecto que chama a atenção nas entidades hospitalares é o processo de mudança por que passam estas entidades em relação à remuneração pelos serviços prestados. Cada vez mais, surgem alterações no funcionamento dos planos de saúde. Também os órgãos públicos e seus recursos escassos têm pressionado essas organizações a receberem valores menores (BORINELLI; BEUREN, 2002, p.4). 
Diante do exposto, a gestão de custos no setor de serviços, principalmente, a de serviços hospitalares, necessita ser investigada, indagada amplamente através da pesquisa, gerando informações e subsídios para os gestores na tomada de decisão.

\section{Metodologia}

A intenção da pesquisa é demonstrar a utilização das ferramentas de custos e suas contribuições junto aos gestores na tomada de decisão em Entidades Hospitalares. A pesquisa é um conjunto de ações, que tem por base procedimentos racionais e sistemáticos, e que visam encontrar soluções para um problema (Silva; Menezes, 2000). É uma atividade de aproximação sucessiva da realidade que nunca se esgota, fazendo uma combinação particular entre teoria e dados (Minayo, 1993, p.23).

Este trabalho caracteriza-se como um estudo exploratório. Segundo Gil (1999, p. 43), "pesquisas exploratórias são desenvolvidas com o objetivo de proporcionar visão geral, de tipo aproximativo, acerca de determinado fato". Quanto à finalidade das pesquisas exploratórias, Gil (1999) apresenta que elas buscam desenvolver, esclarecer e modificar ideias, tendo em vista a formulação de problemas mais precisos ou hipóteses pesquisáveis para estudos posteriores. $\mathrm{O}$ autor destaca, ainda, que pesquisas dessa natureza, habitualmente, envolvem levantamento bibliográfico e pesquisa documental para sua realização.

Sobre pesquisa bibliográfica, Martins (2000) afirma que se trata de estudo para conhecer as contribuições científicas em relação a determinado assunto e tem como objetivo recolher, selecionar, analisar e interpretar as contribuições teóricas já existentes sobre determinado assunto.

\subsection{Procedimentos da Coleta de Dados}

A presente pesquisa foi desenvolvida na cidade de Uberlândia-MG, considerada a maior cidade do interior mineiro, e a segunda do interior do Brasil, atrás apenas de Campinas, com mais de 622 mil habitantes, segundo o Instituto Brasileiro de Geografia e Estatística (IBGE) 2008 e uma área de mais de $4.000 \mathrm{~km}^{2}$. Sua área urbana corresponde a $135 \mathrm{~km}^{2}$, sendo a $16^{\circ}$ maior do Brasil em área urbana. Localiza-se no oeste do estado, na região do Triângulo Mineiro.

O universo desta pesquisa foi composto pelo conjunto de dez (10) hospitais, localizados na cidade de Uberlândia-MG, de acordo com dados do Cadastro Nacional de Estabelecimento de Saúde (CNES), sendo a amostra composta de seis (6) hospitais que se dispuseram a responder o instrumento de pesquisa.

A pesquisa possuiu aspectos exploratórios, que envolveram entrevistas com os gestores ou responsáveis pela análise de custos dos hospitais em estudo, que tiveram ou têm experiência práticas com o problema pesquisado. Participaram da pesquisa 5 (cinco) Hospitais Privados e 1 (um) Hospital Público.

Para a Coleta de dados desta pesquisa, foi utilizada a técnica da entrevista não estruturada que, de acordo com Marconi e Lakatos (1990), é considerada como uma técnica em que o entrevistador tem a liberdade de desenvolver cada situação na direção que considerar adequada; dessa forma, explora mais a questão. Essa técnica consiste em pergunta abertas, as quais, geralmente, são respondidas a partir de uma conversa informal.

A pesquisa utilizou, também, o questionário na coleta dos dados, entregue pessoalmente aos gestores ou responsáveis pela gestão de custos das empresas que compuseram a população alvo. Os dados foram coletados no mês de Março de 2009.

Sobre o questionário, Chizzotti (1991) indica que ele consiste em um conjunto de questões pré-elaboradas, sistemática e sequencialmente dispostas em itens que constituem o 
tema da pesquisa, com o objetivo de suscitar dos informantes respostas por escrito ou verbalmente sobre o assunto acerca do qual estes saibam opinar ou informar, fato que é confirmado por Gil (1999), ao indicar que a sua elaboração consiste basicamente em traduzir os objetivos específicos da pesquisa em itens bem redigidos.

No presente estudo, foram empregados também, na coleta de dados, os procedimentos de pesquisa bibliográfica que é o "conjunto de conhecimentos reunidos nas obras tendo como base fundamental conduzir o leitor a determinado assunto e á produção, coleção, armazenamento, reprodução, utilização e comunicação das informações coletadas para o desempenho da pesquisa" Fachin (1980, p.102).

A principal vantagem da pesquisa bibliográfica está, para Gil (1999, p. 65), "no fato de permitir ao investigador a cobertura de uma gama de fenômenos muito mais ampla do que aquela que poderia pesquisar diretamente".

\section{Análise de Resultados}

Esta seção visa apresentar os principais aspectos que foram investigados junto às empresas que compuseram a amostra desta pesquisa, relacionados principalmente à gestão de custos.

Tabela 1: Perfil do Respondente

Controller

\section{Cargo Ocupado}

Gerente Administrativo

Administrador

Total

Qualificação / Graduação

Contabilidade

Administração

Qualificação / Pós-Graduação

Respondentes
2
2
2
6
Respondentes
3
4
6

Fonte: Pesquisa de Campo realizada pela autora - 2009.

A tabela 01 mostra o perfil dos respondentes quanto ao cargo ocupado e à qualificação dos mesmos (graduação e pós-graduação). Verificou-se que 33,33\% dos respondentes ocupam o cargo Controllers, 33,33\% são Gerentes Administrativos e 33,33\% são Administradores. Com relação à qualificação, 33,33\% dos respondentes são formados em Contabilidade, $50 \%$ em administração e 16,67 possui formação em Administração de Empresas e Contabilidade. Todos os respondentes possuem curso de Pós-Graduação.

Tabela 2: Caracterização das Organizações

\begin{tabular}{c|c|c|c|c}
\hline Empresa & $\begin{array}{c}\text { Tempo/Atuação no } \\
\text { Mercado }\end{array}$ & $\begin{array}{c}\mathbf{N}^{\mathbf{0}} \text { de funcionários } \\
\text { Diretos }\end{array}$ & Número de Leitos & $\begin{array}{c}\text { Atendimentos/ } \\
\text { Convênios }\end{array}$ \\
\hline 1 & 10 a 50 anos & Acima de 500 & Acima de 500 & SUS \\
\hline 2 & 10 a 50 anos & 101 a 300 & 50 a 100 & $\begin{array}{c}\text { Convênio/Particular/ } \\
\text { SUS (Baixa } \\
\text { Complexidade) }\end{array}$ \\
\hline 3 & 10 a 50 anos & 300 a 500 & 50 a 100 & $\begin{array}{c}\text { Convênio/Particular/ } \\
\text { SUS (Alta } \\
\text { Complexidade) }\end{array}$ \\
\hline 4 & 00 a 05 anos & 300 a 500 & 50 a 100 & Convênio/ Particular \\
\hline 5 & Acima de 50 anos & 300 a 500 & 50 a 100 & Convênio/Particular \\
\hline 6 & 05 a 10 anos & 101 a 300 & 50 a 100 & Convênio/Particular \\
\hline
\end{tabular}

Fonte: Pesquisa de Campo realizada pela autora -2009 . 
Observa-se que 50\% (Cinqüenta por Cento) dos hospitais pesquisados já estão no mercado há mais de $10(\mathrm{dez})$ anos, demonstrando a continuidade da organização no mercado regional. Um dos hospitais pesquisados atende somente pelo Sistema Único de Saúde (SUS), que é o Hospital de Clínicas de Uberlândia (HCU), Unidade Hospitalar que pertence à Universidade Federal de Uberlândia (UFU). Foi construído como unidade de ensino para o ciclo profissionalizante do curso de Medicina da extinta Escola de Medicina e Cirurgia de Uberlândia. O HCU se transformou no único hospital público de referência para média e alta complexidade nos municípios do Triângulo Mineiro e do Alto Paranaíba. O restante (cinco hospitais pesquisados) atende convênios e particulares; desses, dois atendem também pelo SUS, sendo, um com alta complexidade e o outro com baixa complexidade.

Tabela 3: Prática do gerenciamento de custos dos serviços prestados

\begin{tabular}{ccc}
\hline Prática da mensuração dos custos & $\begin{array}{c}\mathbf{N}^{\mathbf{0}} \text { de } \\
\text { Hospitais }\end{array}$ & $(\mathbf{\%})$ \\
\hline Sim & 00 & $00,00 \%$ \\
Sim/Parcialmente & 02 & $33,33 \%$ \\
Não & 04 & $66,67 \%$ \\
\hline Total & $\mathbf{0 6}$ & $\mathbf{1 0 0 \%}$ \\
\hline
\end{tabular}

Fonte: Pesquisa de Campo realizada pela autora - 2009 .

Em primeiro momento procurou-se identificar quais as organizações hospitalares, participantes do estudo, praticam ou não a mensuração dos custos dos serviços prestados. A tabela 3 indica que nenhuma das organizações investigadas possui o gerenciamento total de custos, ou seja, não mensuram os custos dos serviços prestados, enquanto $33,33 \%$ das organizações mensuram parcialmente os custos dos serviços prestados e $66.67 \%$ não mensuram esse tipo de custos.

Assim, percebe-se um percentual significativo de organizações que não praticam a mensuração dos custos dos serviços prestados. Estas organizações hospitalares, não terão informações gerenciais para avaliar o desempenho de suas atividades.

\subsection{Organizações que não mensuram os custos dos serviços prestados}

Nesta seção, apresentam-se os resultados da pesquisa referente às organizações que não mensuram os custos dos serviços prestados.

Tabela 4: Motivos para a ausência da mensuração dos custos da prestação de serviços

\begin{tabular}{lll}
\hline Motivos & $\mathbf{N}^{\mathbf{0}}$ de empresas & $\mathbf{( \% )}$ \\
\hline Os custos são irrelevantes para o gerenciamento & 1 & $25 \%$ \\
Falta de um Software (sistema de informação próprio) & 1 & $25 \%$ \\
Não dispõe de recursos financeiros & - & - \\
Por falta de orientação técnica/ Viabilidade & 2 & $50 \%$ \\
Existem preocupações mais importantes & - & - \\
Total & 4 & $100 \%$ \\
\hline
\end{tabular}

Fonte: Pesquisa de Campo realizada pela autora - 2009.

A tabela 4 apresenta os motivos para a ausência da mensuração dos custos na prestação de serviços hospitalares.

Das empresas que não mensuram custos dos serviços prestados, $25 \%$ relata que um dos motivos seria a falta de interesse e necessidade de conhecer os custos de seus serviços, por acharem irrelevantes para o gerenciamento. Outro motivo seria a falta de um profissional qualificado. Fazem também a relação do custo/beneficio, concluindo-se que não seria viável para o hospital dispor de um recurso para ter informações as quais não julgavam importantes. 
Os outros $25 \%$ dizem que não calculam seus custos por falta de Software (sistema de informação próprio para o gerenciamento de custos) que auxilie nesta informação.

De acordo com a tabela, 50\% das empresas investigadas não calculam o serviço prestado por falta de orientação técnica e viabilidade.

Com base nessas informações, foi questionada a política que essas organizações utilizam para definir o preço da prestação de serviço, já que as mesmas desconhecem seus custos.

Tabela 5: Definição dos preços da prestação de serviços

\begin{tabular}{cc}
\hline Definição do preço & $\mathbf{N}^{\mathbf{0}}$ de empresas \\
\hline Utilizando um percentual em tabela já definida (TISS) & 4 \\
Utilizando um percentual em tabela já definida Convênios & 2 \\
Total & 2 \\
\hline
\end{tabular}

Fonte: Pesquisa de Campo realizada pela autora - 2009.

Com relação ao questionamento da definição dos preços da prestação de serviços, os respondentes podiam marcar mais de uma opção. Assim, identificou-se que todas as organizações que não adotam a mensuração de custos em seu controle gerencial definem os preços dos serviços prestados observando o preço do mercado, e 50\% das organizações em estudo acrescentam um percentual que varia de $20 \%$ a $40 \%$ em cima da tabela TISS (Troca de informação em saúde suplementar), e o restante (50\%) precifica, utilizando as tabelas dos convênios.

Em seguida, foi investigado como as organizações hospitalares que não mensuram os custos, ou seja, não possuem o gerenciamento de custo, identificam a lucratividade ou não de suas atividades operacionais. Os dados relativos a esta variável podem ser observados na tabela 6.

Tabela 6: Processo de identificação do Lucro ou Prejuízo - Superávit ou Déficit

\begin{tabular}{lcc}
\hline Identificação do Lucro/Prejuízo - Superávit ou Déficit & $\mathbf{N}^{\mathbf{0}}$ de respondentes & $(\boldsymbol{\%})$ \\
\hline DRE & 3 & $75 \%$ \\
DRE e Fluxo de Caixa & 1 & $25 \%$ \\
Não tem certeza se está tendo lucro ou prejuízo - Superávit & - & - \\
ou Déficit & 4 & $100 \%$ \\
Total & 4 & \\
\hline
\end{tabular}

Fonte: Pesquisa de Campo realizada pela autora - 2009 .

Nota-se que $100 \%$ das organizações investigadas responderam que conseguem identificar se estão tendo lucro ou prejuízo: $75 \%$ por meio da DRE (Demonstração de Resultado do Exercício) e $25 \%$ avaliando a DRE e também o fluxo de caixa.

Nas entrevistas feitas com os gestores hospitalares, verificou-se que os mesmos acreditam que, mesmo não mensurando os custos dos serviços prestados, conseguem identificar quais os serviços proporcionam maior ou menor rentabilidade. Os respondentes afirmaram que 50\% dos serviços de maior rentabilidade são os serviços de alta complexidade prestados pelas Unidades de Terapia Intensiva (UTI) e o restante, 50\% dos resultados, são oriundos da hotelaria. Todas as organizações hospitalares participantes do estudo consideram que o Pronto Socorro (PS) é o serviço com menor rentabilidade. Mesmo que o PS seja a porta de entrada para os serviços de maior rentabilidade, ele é considerado pelos gestores um serviço "Caro" para essas organizações.

Todas as organizações hospitalares participantes do estudo, mesmo não mensurando os custos dos serviços, percebem a importância das informações fornecidas pelo 
gerenciamento de custos para o processo decisório, e demonstram interesse em implementar uma gestão de custos em curto prazo.

\subsection{Empresas que calculam custos dos Serviços Prestados}

Nesta seção, apresentam-se os resultados da pesquisa referente às organizações que mensuram os custos dos serviços prestados.

Das seis organizações participantes da pesquisa, quatro não utilizam nenhum tipo de custeio para mensurar os custos e duas organizações hospitalares mensuram parcialmente os custos dos serviços prestados. Para as duas organizações que mensuram os custos, foram questionados os procedimentos utilizados pelas mesmas.

Tabela 7: Procedimentos da mensuração dos custos da prestação de serviços

\begin{tabular}{lc}
\hline Como é feita a mensuração dos custos & $\mathbf{N}^{\mathbf{0}}$ de empresas \\
Utilizando o Sistema de Informação Integrado (software próprio) & 2 \\
Utilizando planilhas eletrônicas e apurando os custos periodicamente (por tipo de & 1 \\
serviço) & - \\
Utilizando planilhas eletrônicas e apurando os custos médios e aproximados & 2 \\
Total
\end{tabular}

Fonte: Pesquisa de Campo realizada pela autora - 2009 .

Com relação aos procedimentos de mensuração dos custos da prestação de serviços, os respondentes poderiam marcar mais de uma opção. Percebe-se que as duas organizações que utilizam da mensuração dos custos possuem um software próprio para a gestão de custos. Uma das respondentes utiliza também planilhas eletrônicas para apurar os custos periodicamente (por tipo de serviço).

Nas entrevistas, verificou-se que somente uma organização utiliza a classificação total dos custos em fixos, variáveis, diretos e indiretos, e uma organização classifica somente em custos fixos e variáveis.

$\mathrm{Na}$ sequência, será evidenciado, na tabela 8, o método de Custeio utilizado pelas empresas que calculam os custos da prestação de serviços.

Tabela 8: Métodos de custeio utilizados para avaliar os custos

\begin{tabular}{lcc}
\hline Métodos de Custeio utilizados para avaliar os custos & $\mathbf{N}^{\mathbf{0}}$ de empresas & $(\mathbf{\%})$ \\
\hline Custeio por Absorção & 1 & $50 \%$ \\
Custeio Variável/Direto & 1 & \\
Custeio RKW & - & $50 \%$ \\
Custeio ABC & 1 & $100 \%$ \\
Nenhum & 1 & 2 \\
Total & 2 & \\
\hline
\end{tabular}

Fonte: Pesquisa de Campo realizada pela autora - 2009.

Após avaliar os dados acima, observa-se que 50\% das empresas que calculam custos utilizam os métodos de custeio por absorção, custeio variável/direto e custeio $\mathrm{ABC}$, sendo que este utilizado em alguns estudos internos, e $50 \%$ não utiliza nenhum método de custeio.

Na sequência, verificaram-se junto aos respondentes que possuem a gestão de custos quais eram os objetivos para a mensuração dos custos. Nesse caso, os respondentes poderiam marcar mais de uma opção. 
Tabela 9 - Objetivos para apuração dos custos

\begin{tabular}{lc}
\hline Objetivos para apuração dos custos & $\mathbf{N}^{\mathbf{0}}$ de empresas \\
\hline Avaliar o serviço de maior rentabilidade para a empresa & 2 \\
Avaliar o serviço mais oneroso para a empresa & 1 \\
Avaliar qual o serviço poderá deixar de ser oferecido sem afetar negativamente os & - \\
lucros & \\
Avaliar qual a contribuição de cada serviço para o lucro ou superávit & - \\
Apurar o ponto de equilíbrio econômico da empresa & 1 \\
Margem de contribuição por serviço prestado & 1 \\
Gerar relatórios gerenciais & 1 \\
\hline
\end{tabular}

FONTE: Pesquisa de Campo realizada pela autora - 2009.

Percebeu-se que, com a análise dos custos, as organizações hospitalares verificam qual serviço possui maior ou menor rentabilidade. O hospital de Clínicas de Uberlândia, citado anteriormente na presente pesquisa, é uma das empresas que conseguem calcular seus custos e identifica que os procedimentos de alta complexidade, exigem uma estrutura pesada de recursos materiais, humanos e tecnológicos que, se bem gerenciados, geram um bom superávit. A organização verifica também os custos incorridos, determinam o ponto de equilíbrio econômico da empresa, e a margem de contribuição por serviço prestado, gerando relatórios gerenciais que auxiliam na tomada de decisão.

$\mathrm{Na}$ entrevista com o gestor do Hospital de Clínicas, foram citados os seguintes exemplos de relatórios utilizados no gerenciamento de custos: Custo com Serviços de Terceiros; Custo com Pessoal, Água, Energia e Telefone; Custo Médio dos Centros de Custos Básicos; Custo Médio dos Centros de Custos Auxiliares; Custo Médio dos Centros de Custos Finais; Custo Médio dos Principais Procedimentos/SUS; Custo Médio de Produção da Quimioterapia; Custo Médio de Produção da Radioterapia; Gráficos de Custos Diretos Mensais; Análise de Ponto de Equilíbrio e Margem de Contribuição; Custo Médio dos Serviços de Apoio; Gestão do Faturamento por Especialidade; Orçado versus Realizado (Diretoria, Gerência, Setor); Demonstrativo de Receitas/Custo/investimento; Demonstrativo por Centro de Custos e Custos com Material de Consumo.

$\mathrm{Na}$ entrevista feita com a outra organização que possui a gestão de custos, a mesma afirmou que o serviço de maior rentabilidade para o hospital é também o serviço de alta complexidade (UTI) e o menor são os serviços prestados para o SUS, que são de baixa complexidade. Para esta organização, a análise dos custos auxilia na formação de preço dos serviços, apura os custos incorridos, é utilizada para as estimativas do ponto de equilíbrio e também para a análise dos resultados.

Tabela 10: Política de definição do preço da prestação de serviço

\begin{tabular}{lcc}
\hline Definição do preço & $\mathbf{N}^{\mathbf{0}}$ de empresas & $\mathbf{( \% )}$ \\
\hline Atendimento 100\% SUS & 1 & $50 \%$ \\
Aplicando um índice sobre os custos totais dos serviços & - & $50 \%$ \\
Combinando as informações do mercado com as informações de & 1 & \\
custos & & $100 \%$ \\
Utilizando uma fórmula própria. & - & 2 \\
Total
\end{tabular}

Fonte: Pesquisa de Campo realizada pela autora -2009 .

O hospital público não define preço da prestação de serviço, pois é prestador de serviço somente para o SUS, e é este que define a tabela de preços. Observa-se que o segundo 
hospital faz uma combinação de informações de custos de produção com as informações dos preços vigentes no mercado.

Tabela 11: Identificação do lucro ou superávit do período

\begin{tabular}{lcc}
\hline Identificação do Lucro/Prejuízo & $\mathbf{N}^{\mathbf{0}}$ de empresas & $\mathbf{( \% )}$ \\
\hline Comparando a receita com os custos e despesas & 01 & $50 \%$ \\
DRE e Fluxo de Caixa & 01 & $50 \%$ \\
Sabe que tem lucro total e que serviço é mais lucrativo/superávit & - & - \\
Não tem muita certeza de que a empresa dá lucro/superávit & - & - \\
Total & 2 & $100 \%$ \\
\hline
\end{tabular}

Fonte: Pesquisa de Campo realizada pela autora - 2009.

$\mathrm{Na}$ tabela acima, verificou-se que o hospital público identifica o resultado, comparando a receita com os custos e despesas. Já, o segundo hospital, de acordo com os dados apresentados, avalia o resultado por meio da DRE e o Fluxo de Caixa.

\section{Considerações Finais}

Esta pesquisa teve como objetivo principal avaliar a utilização da gestão de custos pelos gestores das organizações hospitalares em suas atividades operacionais e também para a tomada de decisão. A pesquisa foi realizada com os hospitais localizados na cidade de Uberlândia-MG. A amostra pesquisada foi constituída de seis hospitais.

Verificou-se com a pesquisa que os gestores consideram que as informações de custos são importantes, mas que nas organizações hospitalares, devido à complexidade dos serviços prestados, a implantação de um sistema de gerenciamento dos custos requer gastos elevados, além do alto nível de controles internos que deverão ser implantados e avaliados, com necessidade de revisão constante.

Percebe-se que, nas organizações que possuem informações gerenciais geradas a partir dos sistemas de custos, os gestores estarão providos de uma ferramenta que lhes proporcionarão vantagens e diferencial diante de um mercado inovador e competitivo.

Quanto às empresas que dispõem de procedimentos internos relacionados ao cálculo dos custos dos serviços para a geração de informações gerenciais, identificou-se que as mesmas utilizam essas informações de maneira satisfatória, mas que têm muito que desenvolver. O respondente do Hospital de Clínicas relata que a "padronização dos serviços é extremamente importante na definição de um sistema de custos, é uma tarefa bastante complexa e que o hospital tem empenhado em desenvolver uma metodologia que possa atender as expectativas tanto dos usuários internos quanto externos, mas não é tarefa fácil em detrimento de ser uma instituição prestadora de serviço $100 \%$ SUS, com recursos cada vez menores e demanda crescente pelo serviço, além do aspecto político e cultural".

O HCU utiliza da gestão de custos para apurar custos ocorridos, estimar ponto de equilíbrio e margem de contribuição por serviço prestado, gerando informações que demonstram quais serviços geram um maior superávit e fornecendo vários relatórios gerencias para a tomada de decisão. O Hospital particular respondente da pesquisa, que utiliza da gestão de custos, apresentou que aplicam as informações geradas tanto para elaboração do preço da prestação de serviços, quanto para avaliar a rentabilidade do serviço. A organização calcula parcialmente seus custos, porém desconhece qual metodologia é utilizada, considera a gestão de custos importante e que possui projetos de implantar o gerenciamento de custos em médio prazo.

Dessa forma, pode-se afirmar que, no do grupo dos hospitais que calculam e os que não calculam seus custos, existem alguns aspectos comuns, ou seja, percebem seus resultados avaliando a Demonstração de Resultado do Exercício e alguns casos em conjunto com o 
Fluxo de Caixa, exceto para o HCU, que verifica se tem superávit comparando a receita com os custos e despesas. Outro ponto em comum, exceto para o HCU, é que os hospitais colocam preços nos seus serviços fazendo uma combinação de tabelas do governo e convênio e uma comparação com o preço de mercado.

Nesse contexto, verifica-se que há muito a ser explorado na gestão de custos hospitalar. Os gestores percebem a necessidade e a importância da informação de um sistema de custos para que se possa subsidiar de forma eficiente e eficaz o processo decisório e buscar a sustentabilidade econômico-financeira, mas verificou-se com a pesquisa que existe uma escassez na gestão de custos nas organizações hospitalares.

Estas conclusões devem ser consideradas apenas no contexto do universo pesquisado (hospitais localizados na cidade de Uberlândia-MG). Os resultados obtidos neste trabalho não devem ser objeto de inferência para o universo de organizações do mesmo ramo de atividade a nível nacional, nem para organizações de outros setores.

\section{Referências}

ABBAS, Kátia. Gestão de custos em organizações hospitalares. Florianópolis, 2001. Dissertação (Mestrado em Engenharia de Produção) - Programa de Pós Graduação em Engenharia de Produção, Universidade de Santa Catarina.

ALMEIDA, Teófilo R.R. Perspectivas de sobrevivência do hospital. Revista Paulista de Hospitais, São Paulo, n. 5-6, p.104-113, maio/jun. 1983.

BITTENCOURT, O.N.S. O emprego do método de custeio baseado em atividades: Activity-based costing - como instrumento de apoio à decisão na área hospitalar. 1999. Dissertação (Mestrado em Administração), Universidade Federal do Rio Grande do Sul, Porto Alegre.

BORNIA, A. C. Análise Gerencial de Custos: aplicação em empresas modernas. Porto Alegre: Bookman, 2002.

CADERNOS DO TERCEIRO MUNDO. Saúde pública morre à míngua. Rio de Janeiro, n. 210, p. 32-39, jun. 1999.

CARPINTÉRO, J. N. C. Custos na área de saúde: considerações teóricas. VI Congresso Brasileiro de Custos. FEA/USP São Paulo, São Paulo, Anais... 29 de junho a 02 de julho de 1999.

CECILIO, L. C. de O. A modernização gerencial dos hospitais públicos: o difícil exercício da mudança. RAP - Revista de Administração Pública, Rio de Janeiro, v. 31, n. 03, p. 36-47, maio/jun. 1997.

CHIzzotTI, A. A pesquisa em ciências humanas e sociais. Cortez. São Paulo, 1991.

COGAN, S. Custos e Preços: formação e análise. São Paulo: Pioneira Thomson Learning, 2002.

FACHIN, Odília. Fundamentos de metodologia. São Paulo: Atlas, 1993. 
Revista de Administração Hospitalar, v.10, n.1, pp. 3-17, jan/maio, 2013/ Maria Eliana dos Santos; Vidigal Fernandes Martins; Edvalda Araújo Leal

GIL, A.C. Métodos e Técnicas de Pesquisa Social. São Paulo: Atlas, 2002.

HORNGREN, C.T.; DATAR, S.M.; FOSTER, G. Contabilidade de Custos, v. 1, e 2. $11^{\text {a }}$ ed. São Paulo: Prentice Hall, 2004.

LEONE, G.S.G. Curso de Contabilidade de Custos: Contém o Custeio ABC, São Paulo: Atlas, 2000.

MARTINS, E. Contabilidade de Custos. 9. ed. São Paulo: Atlas, 2003.

MARTINS, G.A. Manual para elaboração de Monografias e Dissertações. 2. Ed., São Paulo: Atlas, 2000.

MATZ, A.; CURRY, O. I.; FRANK, G. W. Contabilidade de Custos. São Paulo: Atlas, 1987.

MEDICI, André César \& MARQUES, Rosa Maria. Sistemas de custo como instrumento de eficiência e qualidade dos serviços de saúde. Cadernos Fundap. Rio de Janeiro: FGV, p.4749, jan/abr.1996.

OLIVEIRA, L. M.de; PEREZ JR, J. H. Contabilidade de Custos Para Não Contadores. São Paulo: Atlas, 2000.

PEREZ, J. H.; OLIVEIRA, L. M.; COSTA, R. G. Gestão estratégica de custos. São Paulo: Atlas, 1999.

SANTOS, R. V. Modelagem de sistemas de custo. Revista do Conselho Regional de Contabilidade de São Paulo. São Paulo, ano iv, n. 7, p. 62-74, abr. 1999.

SILVA, A.C.R.. Metodologia da pesquisa aplicada à Contabilidade. São Paulo: Atlas, 2003.

VARTANIAN, G. H.; NASCIMENTO, D. T. O método de custeio pleno: uma abordagem conceitual. Revista do Conselho Regional de Contabilidade de São Paulo. São Paulo, ano iv, n. 9, p. 34-41, set 1999. 